Más allá de las explicaciones comunes:

La incorporación de la tecnología y la cultura digital en el aula

Beyond common explanations:

Incorporating digital technology

and culture into classrooms in México

\title{
Judy Kalman
}

$\overline{\text { Centro de Investigación y Estudios avanzados del IPN, Ciudad de México }}$ judymx@gmail.com 


\title{
Resumen
}

Cada vez más, se espera que una mayor cantidad de docentes en México usen las tecnologías digitales en sus aulas. Sin embargo, se les provee de poca orientación para que transiten de las prácticas del papel y el lápiz a las de la pantalla. Este artículo plantea que el uso de la tecnología digital (o la falta de uso de esta) por parte de los docentes constituye una construcción social en la que múltiples procesos -como la situación de su centro laboral, la forma en que comprenden las tecnologías digitales y el Internet, y sus creencias asentadas sobre la enseñanza y el aprendizaje- coinciden para dar forma a sus prácticas en el aula. La autora basa su análisis de tres docentes que aprenden a usar la tecnología en sus aulas en la ciudad de México en la teoría sociocultural, y más específicamente en nociones relacionadas con interacción social y práctica. Muestra las respuestas heterogéneas por parte de los docentes a esta nueva demanda profesional. Finalmente, concluye que los usos específicos de la tecnología en el aula son el resultado de las formas en las que los docentes articulan las múltiples relaciones y obstáculos que encuentran en su centro laboral.

Palabras clave: tecnología, práctica docente, cultura digital, secundaria, México

\begin{abstract}
More and more teachers in Mexico are expected to use digital technologies in their classrooms. However, little guidance is provided for them to transition from pencil and paper practices to the screen. This article argues that that teachers' use of digital technology (or lack thereof) is a social construction where multiple processes -the realities of their workplace, their understanding of digital technologies and the Internet, and their longstanding beliefs about teaching and learning-coincide to shape their classroom practices. The author builds her analysis of three teachers learning to use technology in their classrooms in México City on socio cultural theory, most notably notions concerning social interaction and practice. She illustrates teachers' heterogeneous responses to this new professional demand. She concludes that specific classroom uses of technology are the result of teachers' particular articulation of the multiple relationships and obstacles encountered in their workplace.
\end{abstract}

Keywords: technology, teacher's practice, digital culture, high school, Mexico 


\section{Más allá de las explicaciones comunes: La incorporación de la tecnología y la cultura digital en el aula}

Hoy en día los responsables de la política educativa avalan el uso de la tecnología digital en las escuelas argumentando que las computadoras y el Internet son ahora parte de la vida contemporánea, y que proporcionar acceso a la tecnología a todos los estudiantes es una cuestión de equidad y justicia. En el informe Horizons 2012, los autores observaron que «Cada vez más, las habilidades tecnológicas son fundamentales para el éxito en casi todos los ámbitos, y aquellos para quienes la tecnología resulta más fácil registrarán más progresos, mientras que los que no tienen acceso o habilidades no podrán progresar» (Johnson, Adams y Cummins, 2012, p. 8).

Esta visión omnipresente de la tecnología (Kuznetsov y Dahman, 2008) se expresa en los documentos oficiales, los programas de estudios y los estándares de enseñanza para el uso de la tecnología. En 2009, las autoridades educativas de México declararon:

En un mundo globalizado, el uso de la Tecnología de la Información y la Comunicación (TIC) se ha convertido en un requisito en el lugar de trabajo y es necesaria para establecer contacto con otras sociedades. Las escuelas no pueden permanecer al margen de estas demandas, sino que deben asumir tareas cada vez más complejas y diversificadas. Los profesores tienen que conformar su trabajo a dichas demandas y satisfacer las necesidades de los tiempos y las exigencias de la sociedad moderna, todo lo cual significa desarrollar nuevas competencias (SEP, 2010, p. 7).

Se da por supuesto que, de alguna manera natural, los profesores realizarán la transición hacia el uso de estas herramientas; y, de hecho, las nuevas directrices curriculares derivadas de la política internacional ponen a los maestros bajo una gran presión para hacerlo ${ }^{1}$. Sin embargo, la investigación

1 El papel que cumplen los organismos internacionales en la formulación de las políticas nacionales en México está más allá del alcance de este documento, y requiere de una discusión aparte. Sin embargo, es necesario tomar en cuenta que los organismos internacionales como la Unesco, el Banco Mundial y la OCDE, y los regionales -como la Cepal y la $\mathrm{OEI}$ - comparten políticas similares en relación con la incorporación de la tecnología en la educación. Promueven la idea de un mundo globalizado, conectado a través del Internet y el conocimiento como el producto más nuevo y codiciado para el desarrollo económico, la estabilidad política y la democratización. Estas organizaciones contemplan la incorporación de la tecnología en las escuelas como un paso importante para llegar a los grupos marginados en las áreas remotas, mejorar los resultados educativos y educar a la fuerza laboral, Ello conducirá eventualmente al logro de la competitividad del mercado y la prosperidad. La distribución de los equipos se promueve como un «imprescindible» para asegurar el cierre de la llamada brecha digital. Estos elementos están presentes en 
ha demostrado lo contrario: desde hace más de una década, los estudios han presentado evidencias que han clasificado y cuantificado la cantidad de equipo que se encuentra ahora en las escuelas y lo poco que se utiliza (Bigum y Lankshear, 1997; Cuban, 2000; Guerrero, 2011; Jara, 2007, McFarlane, 2003).

Las explicaciones estándar, en cuanto a por qué los profesores no pueden o no quieren utilizar la tecnología, se ubican -por lo menos- a lo largo de tres líneas. En primer lugar, algunos ven esta imposibilidad como una cuestión de edad y plantean que los profesores mayores se resisten a usarla, porque sienten que los estudiantes tienen una mejor comprensión que la que ellos tienen de los dispositivos digitales. En segundo lugar, otros la ven como una cuestión de formación de profesores y señalan que estos carecen de oportunidades para aprender las habilidades computacionales que necesitan. En tercer lugar, otros todavía la ven como un problema de abastecimiento de materiales, y sugieren que las escuelas no les proporcionan los programas especializados de computación que son necesarios para las materias académicas (Burbules, 2011; Leu, Hillinger y Loseby, et ál., 1998; SEP, 2010).

Si bien la edad, la formación y los materiales pueden ser factores a considerar, este trabajo pretende ir más allá de estos razonamientos y construir una visión más compleja y matizada de los procesos involucrados al aprender a usar la tecnología digital en los centros educativos. La premisa central es que el uso que hacen los profesores de la tecnología digital (o la falta de uso de la misma) es una construcción social, a partir de la cual varios procesos -las realidades de su lugar de trabajo, su comprensión de las tecnologías digitales y del Internet, y sus arraigadas creencias respecto a la enseñanza y el aprendizajecoinciden en la conformación de sus prácticas en el aula.

Este artículo consta de cinco secciones. En primer lugar, aparece una discusión sobre algunos de los principios de la teoría sociocultural y la noción de práctica social. La segunda sección describe las premisas y las metas del trabajo que realiza el Laboratorio de Educación, Tecnología y Educación $(\text { LETS })^{2}$ con los maestros en la Ciudad de México. La tercera presenta evidencia empírica a través de los bosquejos del trabajo de tres profesoras en sus aulas

las políticas y en los discursos políticos mexicanos (véanse, por ejemplo, las declaraciones del presidente Calderón en Spanish.China, 2010) Para un vistazo a las políticas internacionales, consulte la OCDE, (2010), Sunkel (2006), Jara (2007), Unesco (2013), Para una discusión más crítica, se puede revisar Warschauer (2002) y Collins y Blot (2013).

2 Mi más sincero agradecimiento a Wendy Piza y a Víctor Rendón de LETS por su ayuda con los datos presentados en este documento y su discusión de las versiones anteriores. El trabajo realizado en LETS es intensamente colectivo; cuando me refiero a las ideas colaborativas, utilizo la primera persona del plural nosotros. Cuando hablo de mis ideas y decisiones al escribir este artículo, utilizo la primera persona del singular, yo. También, quiero agradecer a Enna Carvajal por su crítica constructiva de las versiones anteriores. 
como una manera de problematizar -de manera productiva- lo que significa utilizar tecnología en un entorno educativo. La cuarta sección presenta una discusión sobre el trabajo de las profesoras; y, en la última, se esbozan algunas observaciones finales.

\section{La utilización de la tecnología en el aula desde la perspectiva de la práctica social}

En este documento, exploro el proceso de tres maestras que aprenden a utilizar la tecnología en sus salones de clase en la Ciudad de México. El análisis se basa en la teoría sociocultural, especialmente, en las nociones respecto a la interacción y la práctica social (Lave y Wenger, 1991). Según Lave (2011), la teoría sociocultural es una teoría de la práctica social y, como tal, los diferentes tipos de relaciones entre los participantes, los acuerdos institucionales y la distribución del poder son fundamentales para comprender lo que sucede en el aula y por qué (Barton y Hamilton, 1998; Street, 1995).

En la década de 1980, Scribner y Cole (1981) plantearon que toda práctica social implica el uso de una tecnología, habilidades y conocimientos relevantes a dicha práctica. Por su parte, Barton y Hamilton (1998) destacan que las prácticas no son observables, debido a que incluyen aspectos relacionados con las creencias, las ideas y las historias de las personas, así como con las acciones visibles. En la práctica, sin embargo, la participación de la gente se hace visible mediante hechos específicos a los que les imprimen un conocimiento operativo, un conocimiento social y un ethos (Lankshear y Knobel, 2011) relacionado con su participación. Su ethos incluye sus creencias, sus valores y sus prioridades. Para este artículo, este enfoque permite al investigador centrarse en las diversas formas en las que los profesores utilizan las tecnologías digitales, y prestar atención a la manera en la que se relacionan con los diversos factores que afectan la incorporación de tecnología en sus aulas.

En LETS, un grupo de investigación del Departamento de Investigaciones Educativas (DIE) en el Centro de Investigación y Estudios Avanzados en la ciudad de México (Cinvestav), consideramos que las Tecnologías de la Información, la Comunicación y el Diseño (TIC-D, de aquí en adelante) son una poderosa herramienta social que resulta útil para establecer y mantener relaciones sociales (Dyson, 1996), transmitir significados multimodales (Kress, 2003) y representar el conocimiento. La tecnología actual integra múltiples herramientas y opciones expresivas que van desde el diseño editorial básico -como las fuentes, la distribución del texto en una página, y la integración de imagen y escritura- hasta las representaciones dinámicas complejas y sofisticadas -los hipertextos, las composiciones multimodales y las animaciones-. Es más, a través del Internet, la cultura digital se crea y se mantiene mediante interacciones en línea, en tiempo real, en comunicación asincrónica. Ello, además, es posible a partir del desarrollo de comunidades virtuales en las que la participación y el aprendizaje se basan en la posibilidad 
de consultar y ser consultado, de contribuir a una causa común, de recibir y dar retroalimentación abundante, de desarrollar una experiencia situada, y de establecer la acreditación de las comunidades virtuales (Gee, 2003, 2006). En este contexto, el ethos de la colaboración, del conocimiento distribuido (desde la idea de que todos tienen algo que ofrecer) y de la participación en empresas colectivas son una parte integral de la cultura digital (Jenkins, 2006; Lankshear y Knobel, 2011). En nuestro trabajo en LETS, nos hemos planteado preguntas fundamentales relacionadas con la forma en la que los maestros integran los aspectos pedagógicos, operacionales e institucionales de las TIC-D y el ethos de la cultura digital en su práctica docente. Nos interesa comprender lo que hacen y por qué lo hacen (Geertz, 1983), y qué experiencias, conocimientos y know-how podrían contribuir a la creación de un contexto educativo que vaya más allá de lo que Lankshear y Knobel (2011) llaman «hacer lo de siempre» en relación con la enseñanza.

De Certeau señala que el análisis histórico social creó la categoría del individuo, «la base de lo que se supone están formados los grupos» (1988, p. XI). Continúa señalando que, por el contrario, el análisis social ha demostrado que los individuos son el locus en el que interactúan múltiples relaciones, que son a menudo contradictorias e incoherentes. La exploración y la utilización de la tecnología por parte de los profesores pueden ser vistas como una «trayectoria errante» (De Certeau, 1988, p. XVIII) en la que recurren a sus propios medios y recursos para articular elementos heterogéneos. Tales son el discurso oficial, los arreglos institucionales, sus antecedentes profesionales, tradiciones de enseñanza profundamente arraigadas, las sugerencias que surgen de su participación en las reuniones de LETS, sus creencias sobre la enseñanza y el aprendizaje, entre otros.

En este caso, el análisis se centra en los esfuerzos de tres profesoras participantes por comprender y utilizar centros tecnológicos en sus diversas formas de integrar una pluralidad de determinantes sociales. Respecto a ello, Mulcahy (2012) propone que, en cualquier evento de enseñanza, confluyen múltiples factores tributarios para crear una instancia específica del trabajo de los profesores. Esta autora señala que las distintas formas de enseñanza son un conjunto de procesos, historias, conocimientos y know-how. De acuerdo con ello, Gee argumenta que somos «seres situados»:

Lo cual se puede entender como una coordinación significativa entre elementos humanos y no humanos. Además de incluir a las personas en sí mismas, los elementos humanos de las coordinaciones incluyen cosas tales como las formas de pensar, actuar, sentir, moverse, vestirse, hablar, gesticular, creer y valorar de las personas, y los elementos no humanos incluyen cosas tales como las herramientas, los objetos, las instituciones, las redes, los lugares, los vehículos, las máquinas, los espacios, los edificios, etcétera (citado por Lankshear y Knobel, 2011, p. 44.). 
Aquí el objetivo es entender la situacionalidad de estos maestros y sus esfuerzos para utilizar la computadora y el Internet en el aula. Además, trato de entender la manera en la que su comprensión de la información, la comunicación y las tecnologías de diseño (TIC-D) ${ }^{3}$ y la cultura digital está mediada por su destreza en la operación del equipo, su interpretación del discurso oficial y los requisitos curriculares, sus creencias acerca de sus estudiantes, su postura pedagógica, y su disposición para adoptar ciertos riesgos y probar nuevos enfoques en su práctica docente. Sobre este punto, Sutherland, Robertson y John señalan que los profesores «tienen mucho que aprender para explotar plenamente el potencial de las nuevas tecnologías en la transformación del aprendizaje. La incorporación de las TIC desafía con frecuencia las formas bien establecidas de enseñar y aprender. Esto a veces implica un doloroso replanteamiento» $(2009$, p. 6$)$.

\section{El trabajo con los profesores}

En LETS, organizamos grupos de trabajo con los profesores, quienes colaboran no solo con sus colegas, sino también con investigadores, estudiantes de grado y estudiantes de postgrado. Los profesores participantes son voluntarios; y, en la mayoría de los casos, se han enterado de nuestros grupos por otros profesores o por medio de una invitación por escrito que enviamos a su escuela.

Cada año escolar, comenzamos con un taller intensivo de una semana de duración al que llamamos «Semana de Instalación». Durante dicha semana, exploramos diferentes aspectos de los conocimientos digitales, la cultura y la práctica. A esto le damos seguimiento durante el año escolar mediante entre cinco y seis sesiones de trabajo, que tienen lugar un día a la semana en el campus del DIE-Cinvestav. Cabe anotar que los profesores cuentan con el permiso de sus autoridades para asistir. También, se realizan algunas visitas a los salones de clase de dichos profesores.

En el LETS, los profesores exploran lo que denominamos «herramientas universales», es decir, el software que uno puede encontrar en cualquier computadora de un cibercafé (aunque en diferentes versiones), el software gratuito en línea y distintas opciones de comunicación. Estas opciones no

3 En la literatura de investigación y en otras publicaciones, la tecnología digital y la conectividad a menudo se resumen como tecnología de la información y la comunicación, y se conocen como TIC. Sin embargo, este acrónimo deja fuera una parte muy importante de la cultura digital, a saber, las múltiples herramientas, plataformas, espacios virtuales y recursos que usa la gente para hacer sus propios diseños en una variedad de modos de representación. Además, a menudo se olvida la «C», lo cual excluye las herramientas de gran alcance para el intercambio que ofrece la conectividad. Por ello, lo que aquí sugerimos es ampliar el término al de Tecnología de la Información, de la Comunicación y el Diseño (TIC-D), como una forma de volver a poner en la escena al usuario de la tecnología. Respecto a ello, se puede consultar Buckingham (2007). 
suponen gasto alguno para los profesores y son herramientas que también sus estudiantes podrán usar. Las utilizamos con diferentes propósitos, tales como el de seleccionar y analizar información, establecer comunicación con los demás, y desarrollar actividades que incluyan el diseño de objetos culturales como carteles, vídeos o mapas animados. Por esta razón, para referirnos al uso de la tecnología, en este trabajo, utilizamos la abreviatura TIC-D, que corresponde a las tecnologías de la información, la comunicación y el diseño (en lugar de la abreviatura más común TIC, que corresponde a la tecnología de la información y la comunicación).

Cabe anotar que, a menudo, ofrecemos a los profesores guías técnicas diseñadas por el LETS para el manejo de una herramienta en particular, o para enseñarles cómo encontrar recursos en línea. También, les ofrecemos opciones de búsqueda y oportunidades para consultar con sus colegas y familiarizarse con un determinado recurso. Los profesores son invitados a discutir sus planes de estudio y a planear actividades de aprendizaje para sus estudiantes que involucren tanto los usos en línea y fuera de línea de la computadora, como otros recursos. Ellos llevan estas propuestas a sus salones de clase, las ponen en práctica y, luego, reportan sus experiencias al grupo. Ahí, analizamos colectivamente lo que resultó exitoso, y cualquier deficiencia o idea relacionada con su práctica docente.

Durante la Semana de Instalación de 2012, participó un grupo conformado por dieciocho profesores de Arte, Lenguaje, Historia y Geografía; así como seis maestros de recursos informáticos, de un igual número de laboratorios de computación en escuelas secundarias públicas. Desarrollamos una secuencia en torno al tema de la esclavitud hoy en día, un tema que podía ser de interés para todos los maestros participantes, y les propusimos que para el final de la semana produjeran un infográfico. En cada sesión, utilizamos recursos como Google Maps, Google Docs y Book Markers, entre otros, como una forma de modelarlos como posibles herramientas para el salón de clases. Nuestras sesiones incluyeron la búsqueda de información y la utilización de diferentes tipos de recursos (vídeos, mapas, testimonios, informes, políticas, imágenes, gráficos); el diseño de los productos intermedios que utilizarían en su infográfico, la organización de grupos de revisión, y el armado del proyecto final.

En cada sesión, creamos contextos para diferentes tipos de interacciones y actividades con la intención de ayudar a los profesores a lograr más de lo que ellos podrían si trabajaran solos (Gee, 2006; Vygotsky, 1978). En algunos casos, organizamos discusiones con todo el grupo, sesiones de trabajo en grupos pequeños, o diálogos uno a uno utilizando herramientas de comunicación sincrónica. Buscamos información de manera colectiva; y discutimos diferentes formas de registrarla y representarla, así como posibles opciones para compartirla. A los maestros se les dio la oportunidad de trabajar directamente con las nuevas herramientas, de interactuar con sus colegas, de dar y recibir retroalimentación sobre su trabajo, y de colaborar conjuntamente en proyectos comunes. El objetivo era presentarles no solo los recursos tecnológicos, 
sino insertarlos en contextos pedagógicos y modelar formas de participación e interacción. Intentamos mostrarles formas innovadoras de organización, de analizar las relaciones en el salón de clase, y de ofrecerles alternativas viables a «hacer lo de siempre» en sus clases. En el contexto de las escuelas en México, en el que la tendencia es introducir la tecnología en los rituales escolares existentes, nuestro taller tiene dos objetivos y prioridades igualmente importantes: facilitar el uso de las herramientas digitales en el aula; $y$, al mismo tiempo, crear actividades de aprendizaje significativas para los profesores y sus estudiantes.

\section{La enseñanza de la tecnología en las escuelas secundarias públicas de México}

Las semblanzas de las maestras que aquí se presentan forman parte de un estudio en curso, que gira en torno a las complejidades de la utilización de la TIC$\mathrm{D}$ en las aulas de las escuelas secundarias públicas de México. Debido a que el proyecto aún se encuentra en proceso, los resultados que aquí se presentan son preliminares; en el momento de la redacción de este documento, seguíamos reuniéndonos con los maestros y visitando sus aulas. También, estamos procesando los datos recopilados (transcribiendo vídeos, organizando los productos de los maestros y los estudiantes, realizando entrevistas, registrando en gráficas su participación en los medios sociales, recolectando mensajes de correo electrónico, y armando carpetas con los trabajos de los maestros).

Todos los profesores a los que se hace referencia en este artículo son egresados de la Escuela Nacional de Maestros en la Ciudad de México y continuaron su formación hasta obtener un certificado de educación secundaria. Hasta 1984, los maestros en México pasaban directamente del tercer grado de educación secundaria a la escuela normal (ya fuera a la Escuela Nacional de Maestros o a una de las escuelas ubicadas en los Estados). Dependiendo de su edad, los profesores cuentan con un título de licenciatura en educación o con un grado de normalista.

Las maestras que aparecen en este estudio trabajan en escuelas públicas y comparten condiciones de trabajo similares. Sus grupos suelen ser grandes, dentro de un rango que va de 35 a 45 estudiantes por grupo. Por lo general, cambian de aula entre un período y otro, en lugar de que sean los alumnos los que circulen de aula en aula. Una consecuencia inmediata de este tipo de organización es que, en cada movimiento, los libros o los materiales que estas llevan consigo a clase tienen que ser empacados y transportados. Además, la mayoría de las escuelas tienen un laboratorio de computación (que los profesores llaman Red Escolar), en los que se concentran las computadoras. La mayoría de los laboratorios comparte un uso similar del espacio: las computadoras están encima de unas mesas colocadas en forma de herradura, y los estudiantes se encuentran mirando hacia las paredes. Cuando hay demasiados equipos o la habitación es pequeña, también, se puede colocar una hilera de mesas en 
medio de la habitación. En algunos casos, las computadoras son laptops nuevas equipadas con sistemas operativos de tecnología de punta, pero, en muchos otros, el equipo es obsoleto. En la mayoría de las veces, lo que hay es una combinación de tecnologías nuevas y viejas. En general, la conexión a Internet no es confiable y se satura rápidamente cuando los estudiantes están trabajando al mismo tiempo.

Gráfico I. Distribución típica del laboratorio de computación en las escuelas secundarias públicas de la ciudad de México

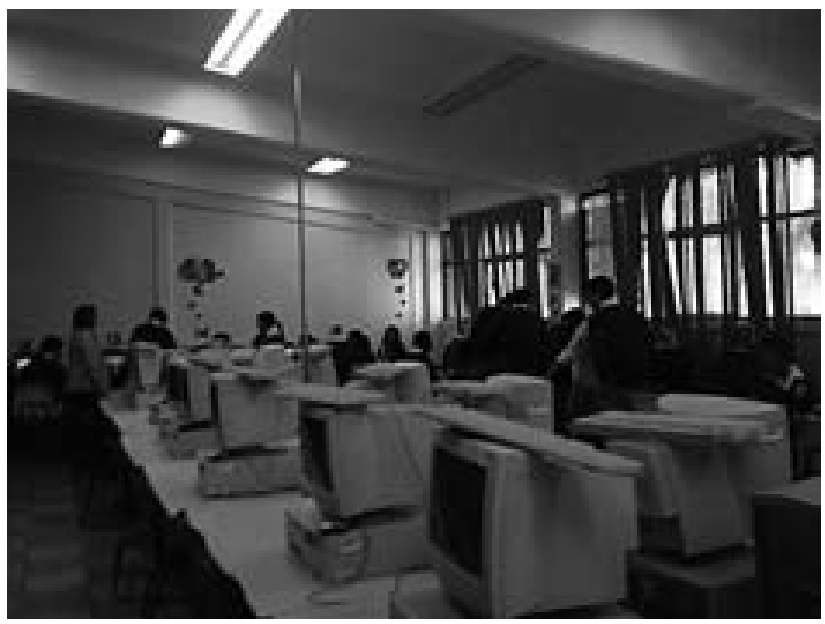

Fuente: Archivo del proyecto

El plan de estudios de secundaria incluye estándares de enseñanza para el uso de la tecnología en el aula, que se basan en los lineamientos de la Unesco y de la Sociedad Internacional para la Tecnología en la Educación (ISTE, por sus siglas en inglés) (SEP, 2011, pp. 65-66). Dentro de este marco, se espera que los profesores desarrollen proyectos de aprendizaje para los estudiantes utilizando la tecnología. Se hace hincapié en que en estos proyectos los profesores deben cumplir con los siguientes parámetros:

- Utilizar herramientas que promuevan la comprensión de conocimientos y conceptos, y que exploren cuestiones y temas de interés

- Planificar y llevar a cabo actividades de investigación con sus alumnos utilizando la tecnología

- Servirse de herramientas de comunicación, como el correo electrónico, los blogs y los foros en línea

- Promover la cooperación

- Desarrollar proyectos de investigación que ofrezcan soluciones a problemas auténticos basados en la vida real 
- Utilizar herramientas como procesadores de texto, programas de datos y procesadores de datos

- Usar los medios sociales y participar en redes de aprendizaje

Para dar una clase utilizando tecnología, los profesores tienen que llevar a sus estudiantes al laboratorio de computación, lo cual implica programar y reservar con anticipación el uso del laboratorio. Si bien la política oficial en México está orientada a promover el uso de la TIC-D en este nivel escolar, para utilizar el aula de informática, los maestros a menudo se enfrentan a varios obstáculos. Entre ellos, se encuentran las reuniones programadas en el laboratorio; las tareas administrativas asignadas por el director al profesor de recursos tecnológicos; clases especiales sobre temas de moda, como la drogadicción, el bullying o la obesidad; realización de inventarios de equipos; y que el laboratorio esté siendo utilizado para aplicar exámenes o como espacio de almacenamiento. Estas son algunas de las razones mencionadas por los maestros, y por las cuales no les es posible utilizar las instalaciones de sus escuelas. Además, se debe considerar que, para ello, tienen que movilizar aproximadamente a cuarenta jóvenes del aula al laboratorio de computación y esto puede restar hasta quince minutos de los períodos de clase de cincuenta minutos (Guerrero, 2011). Asimismo, en las escuelas más grandes, el laboratorio puede tener una gran demanda y los maestros tienen que esperar hasta seis semanas para que llegue su turno para utilizarlo.

Durante una de nuestras visitas a los laboratorios de computación de las escuelas, nos dimos cuenta de que la conexión a Internet era muy lenta y que los estudiantes estaban usando un navegador más bien obsoleto. En una de esas visitas, pregunté al maestro de recursos de tecnología acerca de esto, y me explicó que «estas máquinas fueron donadas por el Gobierno del Distrito Federal (GDF) y que están configuradas para que usted no pueda descargar en ellas ningún programa nuevo. Así que si queremos utilizar un navegador distinto, lo tenemos que descargar cada día. Cada vez que se apaga la computadora, cualquier archivo nuevo se borra, incluso si los guarda». Respecto a ello, cabe anotar que la distribución de los equipos por parte del GDF fue un programa de gran alcance durante la administración 2006-2012, y todas las computadoras comparten esta misma característica. Ello significa que, aunque las escuelas tienen máquinas, aún antes de ser instaladas todas fueron gravemente mutiladas. Probablemente, el obstáculo encontrado al descargar programas se instaló para evitar que los usuarios visitaran lugares prohibidos y descargaran materiales y software indeseables, aplicando la lógica de la «orientación paternal» (o, en este caso, de la orientación escolar). Si bien esto puede responder a ideas relacionadas con mantener a los estudiantes concentrados en sus tareas, al restringir el acceso a las páginas web y al software, también, se anula el propósito de explorar, localizar y seleccionar información para el aprendizaje académico. 
Los breves esbozos que aquí se presentan sobre el trabajo de tres profesoras están basados en sus relatos e informes acerca de las actividades que realizan en sus salones de clase, en el análisis del trabajo de sus alumnos y en observaciones en sus aulas. Los esbozos no pretenden ser un recuento exhaustivo, sino un muestrario de las situaciones que las maestras han reportado y de los procesos específicos que han vivido para integrar los elementos «algunas veces incoherentes y a menudo contradictorios» discutidos anteriormente (De Certeau, 1988). La primera maestra es Adriana, que enseña Geografía en primero de secundaria. En el plan nacional de estudios, el programa de estudio de esta asignatura está organizado en torno a las "competencias», definidas como la integración de conocimientos, habilidades, actitudes y valores. Las otras dos profesoras, Hilda y Lucía, enseñan Español. En México, el programa de lenguaje para los grados de primero a tercero de secundaria se divide en tres ámbitos: literatura, técnicas de estudio y participación social. El currículo aboga explícitamente por un «enfoque de práctica social». Sin embargo, al hacer un escrutinio más cercano, queda claro que los contenidos de estudio están organizados en torno a los géneros textuales, las habilidades lingüísticas aisladas y la gramática. Es importante señalar también que todas las maestras tenían un conocimiento práctico previo para utilizar la computadora y navegar por Internet ${ }^{4}$.

En cuanto al año escolar, este se divide en cinco períodos de calificación de aproximadamente dos meses cada uno, y se espera que los maestros cubran todos los temas que figuran en sus programas de estudio. Recientemente, a partir de la propuesta del Banco Mundial, el rendimiento de lectura en los estudiantes se mide en "palabras por minuto» en cada período de calificación, y la calificación que obtienen se incluye en su boleta de notas. Los profesores de Español son los responsables de administrar estos exámenes individualizados, lo cual reduce su tiempo de clase para otras actividades.

\section{Adriana: «Les permitió pensar un poco»}

Durante los últimos doce años, Adriana ha enseñado Geografía en una escuela secundaria ubicada en un barrio de clase obrera en el lado este de la Ciudad de México. Antes de llegar a LETS, participó en dos cursos prácticos para utilizar la tecnología en el salón de clases. El primero consistió en un curso general sobre el uso de la tecnología en el aula; y el segundo fue un curso sobre el uso de los pizarrones electrónicos. Ella está familiarizada con una serie de herramientas digitales, y es una ávida usuaria del teléfono inteligente, del envío de mensajes, de los mapas de Google y del correo electrónico. También, usa la cámara del teléfono, en particular, para tomar fotografías de los elementos

4 Aunque un número significativo de los profesores que colaboran con LETS puede comenzar sin un conocimiento práctico del uso de la computadora o de las prácticas más difundidas (el correo electrónico, por ejemplo), para los propósitos de este trabajo, elegí profesoras con un grado de conocimiento similar. 
geográficos que pueden ser útiles en la escuela. Como parte de su trabajo, suele ir al laboratorio de computación con sus alumnos (una vez por semana), y les pide -sobre todo- que busquen información.

En su práctica docente, está particularmente interesada en desarrollar la «capacidad de investigación» de los estudiantes. Está convencida de que, para los estudiantes, la tecnología es un medio de comunicación y un recurso que deben tener al alcance de la mano. Para usar la tecnología en su trabajo, se enfoca en la manera de facilitar el uso y la comprensión de las TIC, debido a que «muchos programas de software son muy técnicos».

Al principio del año escolar, Adriana no podía utilizar el laboratorio de computación de la escuela, porque todo el equipo estaba siendo inventariado. En noviembre, sus estudiantes hicieron un informe sobre las diferentes conceptualizaciones del origen del sistema solar. Primero, les pidió que buscaran información sobre varios científicos medievales y del Renacimiento, y que ubicaran sus teorías. La idea era que los estudiantes organizaran cronológicamente las teorías, y que -luego- compararan las conceptualizaciones para ver si podían identificar de qué manera las primeras se habían transformado y cambiado con el tiempo. Sin embargo, esta tarea se transformó en un informe sobre la biografía de cada científico. El encargo original perdió su calidad analítica y abrió la puerta para que los estudiantes simplemente reprodujeran en una presentación de PowerPoint la información que habían encontrado.

En enero, Adriana comenzó a trabajar con sus estudiantes sobre el tema del patrimonio nacional. Estos habían visitado varios museos y ella quería que elaboraran un folleto turístico que combinara su experiencia de ir a los museos, con información acerca de las exposiciones, como una especie de invitación para que otros los visitaran. Al igual que en el caso de los científicos, cuando los estudiantes fueron al laboratorio de computación, Adriana cambió las indicaciones y les dijo que escribieran un folleto sobre su patrimonio nacional. Dio instrucciones específicas, señalando que debían responder a las siguientes preguntas:

- ¿Cuál es la definición de patrimonio nacional?

- ¿Qué tipos de patrimonio hay?

- ¿Qué es el patrimonio tangible?

- ¿Qué es el patrimonio intangible?

Aparte de definir el tipo de texto (folleto) y de presentar las preguntas, no dio otras instrucciones. Los estudiantes comenzaron a trabajar en grupos pequeños, y procedieron de diferentes maneras. Algunos buscaron «folleto» en Google para tener una idea acerca del aspecto que debía tener su producto final. Otros procedieron a buscar definiciones, y a copiarlas y pegarlas en una pantalla en blanco. Un equipo abrió un proyecto en Microsoft Publisher, y empezó a copiar y a pegar la información en él. Algunos más dividieron una página de su cuaderno en tres columnas y copiaron a mano lo que aparecía en la pantalla. 
Gráfico II. Estudiantes copiando de la pantalla a sus cuadernos

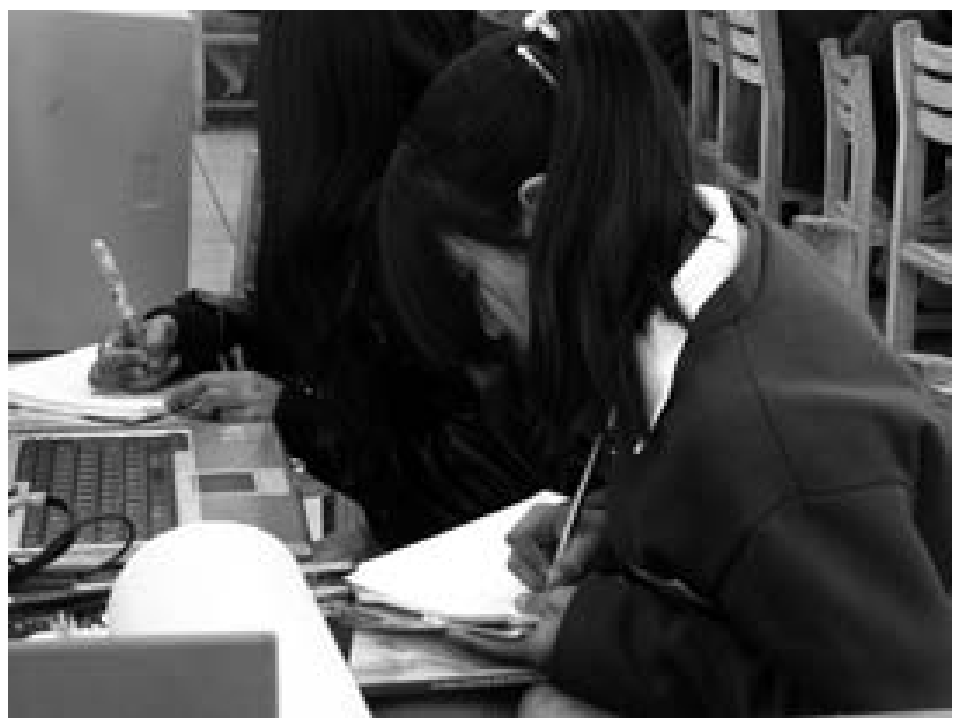

Fuente: Archivo del proyecto

Gráfico III. Trabajo de los estudiantes en hoja de cuaderno doblada en tres

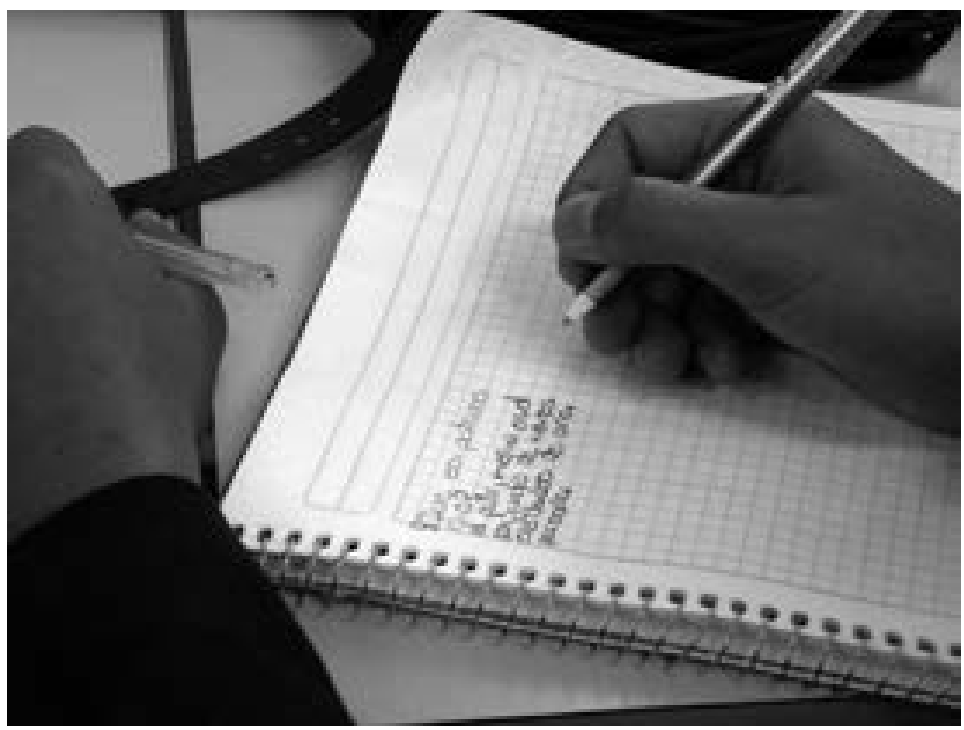

En el texto se lee «¿qué es el patrimonio? Patrimonio es la serie de vienes eredado por una persona». [La transcripción reproduce la ortografía de la estudiante. La pregunta está escrita en rojo, la respuesta en negro] Fuente: Archivo del proyecto 
Adriana daba vueltas por la habitación y supervisaba a sus estudiantes. Cuando se dio cuenta de que muchos de ellos estaban usando Wikipedia, ella gritó dirigiéndose al grupo: «Y no utilicen Wikipedia». Uno de los estudiantes le preguntó: «¿Por qué Wikipedia no?». Después de esperar varios segundos, respondió «La información no es confiable».

Continuó recorriendo el laboratorio de computación. Observó a otro estudiante durante varios minutos y, antes de llegar a su pantalla, apuntó hacia su trabajo y declaró: «Esto a mí no me sirve». No me quedaba completamente claro por qué había dicho eso, y pensé que, quizás, se debía a que todo el texto había sido copiado de una fuente anónima. Al revisar el trabajo que habían entregado los estudiantes, y a pesar de que en el pasado a menudo había aceptado trabajos del mismo tipo, se decepcionó al descubrir que el contenido -en su mayor parte- había sido reproducido directamente de las fuentes electrónicas (ya fuera copiado y pegado directamente en el folleto o copiado a mano en sus cuadernos). Unos días más tarde, en una sesión de chat conmigo, me informó que en el salón de clases les había dado a sus estudiantes una impresión de una pantalla en blanco de PowerPoint y que les había pedido replantear su trabajo y escribir sus propios textos. Yo le pregunté cómo había apoyado el proceso de composición de sus alumnos. Ella respondió que un alumno había leído en voz alta para el grupo el libro de texto, y que luego «poco a poco» los demás habían escrito sus propios textos. Cuando le pregunté cómo pudieron haber transformado lo que habían leído en su libro de texto en escritos propios, me respondió que «estas pantallas les permitieron pensar un poco». De esta manera, Adriana expresa la creencia de que los materiales (y no necesariamente la actividad o sus interacciones con ellos) habían determinado el trabajo que produjeron los estudiantes; quizás, suponiendo que antes los estudiantes no estaban pensando.

\section{Hilda: «Dar el tema»}

Hilda es una joven maestra con cinco años de experiencia docente. Antes de comenzar su trabajo en LETS ya estaba familiarizada con la computadora y el Internet, y había tomado un curso de informática en el Centro de Capacitación para el Trabajo Industrial (Cecati). Tenía un conocimiento práctico del software de procesamiento de textos, hojas de cálculo y presentación. También, mencionó que tenía cuentas de Facebook y Microsoft Messenger, que utilizaba la computadora para descargar las fotos de su cámara y otros dispositivos como un teléfono móvil y cajeros automáticos. Informó que utiliza Facebook para cuestiones familiares y que, a veces, cuando necesita ayuda para hacer algo nuevo en el equipo, consulta a otros o pide ayuda a los estudiantes. En su práctica docente, utiliza la tecnología para «investigar los temas», escribir planes de lecciones, y desarrollar un "plan de trabajo» periódico, que entrega a su director. Sin embargo, dijo que ella rara vez lleva a los estudiantes al laboratorio de computación. Está convencida de que, por lo general, sus alumnos no se sienten atraídos por la escuela y de que rara vez están interesados en las tareas. 
Antes de nuestra reunión de septiembre de 2012, preguntamos a los profesores por correo electrónico sobre las actividades que habían organizado durante el primer mes de clases con sus alumnos. Hilda señaló que prácticamente no había utilizado la tecnología durante ese mes, puesto que era el final del período de calificaciones y ella estaba atrapada en el papeleo.

Las dos actividades que Hilda reportó en la reunión de octubre fueron una tabla de doble entrada y un mapa mental, producidos por los estudiantes en la computadora, utilizando el Internet para localizar información e imágenes. Para dicho período, los temas de estudio que presenta el plan de estudios incluyen los «mitos y leyendas» como línea de literatura, y «la presentación de la información» como parte del área correspondiente a los hábitos de estudio Su lectura del plan de estudios es bastante literal y ella cree, al igual que muchos de los profesores con los que hemos trabajado, que su trabajo es enseñar cada tema, uno por uno. La típica organización de una unidad temática en este nivel es introducir el tema, presentar las definiciones y características, dar una tarea de lectura y pedir a los alumnos que escriban un resumen, un guión o que hagan una presentación oral.

En este caso, como en otros que hemos documentado, Hilda desarrolló procedimientos para cubrir el contenido curricular y combinó los contenidos a partir de dos áreas curriculares diferentes. Los estudiantes crearon un gráfico y un mapa conceptual (un tema requerido en el área de estudio) sobre los mitos y las leyendas (un tema requerido en el área de literatura). No obstante, no está claro si en realidad leyeron o discutieron las obras como parte de la comparación y del contraste. Cuando le pedí que evaluara esta tarea, expresó su preocupación por que lo que les había pedido a los estudiantes podría distorsionar el mandato curricular: «Me preocupa que mi tema [LETS] no coincide [con el tema curricular] [con lo que hicieron los estudiantes.] No se trata de buscar información, se refiere a la representación de la información». Hilda parece haber fragmentado la búsqueda de información de su registro, y parece que no establece la conexión entre registrar, representar y analizar la información. Esto, al menos en parte, puede deberse a su entendimiento del currículo de Español, el cual también separa explícitamente estas actividades.

En el laboratorio de computación, los estudiantes completaron dos tareas. Para la primera, crearon la tabla descrita anteriormente mediante la búsqueda de las características de los mitos y de las leyendas, y las compararon para establecer las diferencias entre ambas. En segundo lugar, la profesora pidió a sus estudiantes que hicieran un mapa conceptual de las nociones de mitos y leyendas. Hilda creía que estas actividades no podrían ser organizadas adecuadamente, debido a que no había suficientes computadoras en su escuela para que cada estudiante tuviera la suya, y que los estudiantes debían trabajar en el laboratorio de manera individual.

A continuación, se muestra un ejemplo del trabajo de un estudiante. La información fue copiada y pegada, o estrechamente parafraseada de Yahoo. Sin embargo, refleja la sintaxis y la forma de expresarse del estudiante. Se incluyen 
Tabla I. Comparación de los mitos y leyendas por parte de los estudiantes

\begin{tabular}{|c|c|}
\hline Características & Diferencias \\
\hline Pueden ser ficticias o verdaderas & $\begin{array}{l}\text { El tiempo y el espacio es muy indefinido } \\
\text { en los mitos en las leyendas es definido }\end{array}$ \\
\hline Ambos son de tradición oral & $\begin{array}{l}\text { En el mito es demasiada exagerada la } \\
\text { historia y en la leyenda no }\end{array}$ \\
\hline $\begin{array}{l}\text { Lo que relatan era aceptado } \\
\text { por la comunidad }\end{array}$ & $\begin{array}{l}\text { En las leyendas son personajes normales y } \\
\text { en el mito son dioses monstruos o gigantes }\end{array}$ \\
\hline Pasó hace bastante tiempo & $\begin{array}{l}\text { En el mito trata de explicar la existencia } \\
\text { del hombre, las conductas, los fenómenos } \\
\text { naturales, las instituciones y en la leyenda } \\
\text { no }\end{array}$ \\
\hline
\end{tabular}

Fuente: Elaboración propia

La mayoría de las tablas de los estudiantes son muy similares a la anterior. Para crear el mapa mental de estos mismos conceptos, este estudiante en particular leyó un mito en línea, lo copió, lo pegó y lo ilustró. No existe ninguna relación aparente entre las dos partes de la tarea. El único denominador común parece ser que fueron hechas en la computadora y son parte de la construcción curricular del tema. El resumen de las características de los mitos y las leyendas es independiente del mito que ellos leyeron, y su presentación sintetiza su contenido, pero no ilustra ninguna de las características enunciadas.

En esta actividad, Hilda se aventuró por primera vez en el laboratorio de computación y diseñó para sus estudiantes dos actividades. Enfrentó, también, problemas de organización, y pidió que los alumnos trabajaran individualmente, en parejas y en pequeños grupos. Para ella, esto era nuevo. Respecto a ello, se debe considerar que su labor y el trabajo de sus estudiantes son característicos de las prácticas escolares arraigadas en las escuelas secundarias mexicanas. Los profesores tienden a hacer preguntas cerradas y los estudiantes a encontrar respuestas en línea y a reproducirlas. Este tipo de tareas eran comunes antes del arribo de las computadoras en las escuelas: los estudiantes copiaban a mano o cortaban textos informativos e ilustraciones compradas en las papelerías locales. Mientras que la tarea de asignar la resolución de preguntas puntuales es una tarea común, la reacción de Hilda en esta ocasión no lo es. Por lo general, estaba convencida de que sus estudiantes eran apáticos; $y$, a la vez, estaba muy sorprendida por el compromiso e interés que mostraban por utilizar las computadoras en clase. No creía que estarían interesados y se alegró cuando sí estuvieron.

Otra actividad que reportó en noviembre fue pedir a los estudiantes que, en lugar de un informe escrito, produjeran un vídeo para uno de sus proyectos. $\mathrm{La}$ «monografía» es un tema en el plan de estudios y es parte de la línea de estudio. Ella cubrió el tema presentando a sus estudiantes la información acerca de 
«lo que es una monografía», «los tipo de monografías que existen» y «las características de una monografía». Sus estudiantes, también, leyeron la explicación en su libro de texto y ella les pidió tomar notas sobre el tema. Hilda asignó esta tarea después de una sesión de LETS en la que los profesores también crearon un video. Siguiendo las sugerencias del plan de estudios, se había pedido a los estudiantes que, para su video, eligieran un tema reciente de su clase de geografía o de biología. Finalmente, su trabajo fue similar al del ejemplo de la leyenda y el mito: crearon la mayor parte de su video copiando información e imágenes, y colocándolas en Movie Maker. No obstante, incluso con estas limitaciones, Hilda se está moviendo en una nueva dirección al considerar el uso de otros productos académicos diferentes a los ensayos, resúmenes e informes.

Durante la primavera de 2013, LETS sostuvo una serie de reuniones virtuales con los profesores, e Hilda participó activamente. Uno de los cambios más recientes en su práctica docente es que ha empezado a redefinir la forma en la que asigna tareas a los estudiantes. Esto se ilustra mejor con sus intentos de alentarlos a proponer sus propias preguntas de investigación después de presentar el tema en clase. La situación más difícil con la que se ha topado es que las preguntas de los estudiantes son mucho más amplias que las que ella normalmente hace. Por lo tanto, ha tenido que desarrollar nuevos enfoques para las discusiones en clase, y para organizar y orientar su trabajo en el laboratorio de computación. En marzo y abril, Hilda intentó una manera diferente de organizar una unidad temática sobre las lenguas indígenas de México, un tema del programa de estudios de primero de secundaria. Empezó enviando un correo electrónico a sus alumnos para invitarlos a colaborar en la elaboración de un mapa para localizar los principales grupos lingüísticos en México.

Gráfico IV. Grupos lingüísticos de México, creado por Hilda y sus estudiantes

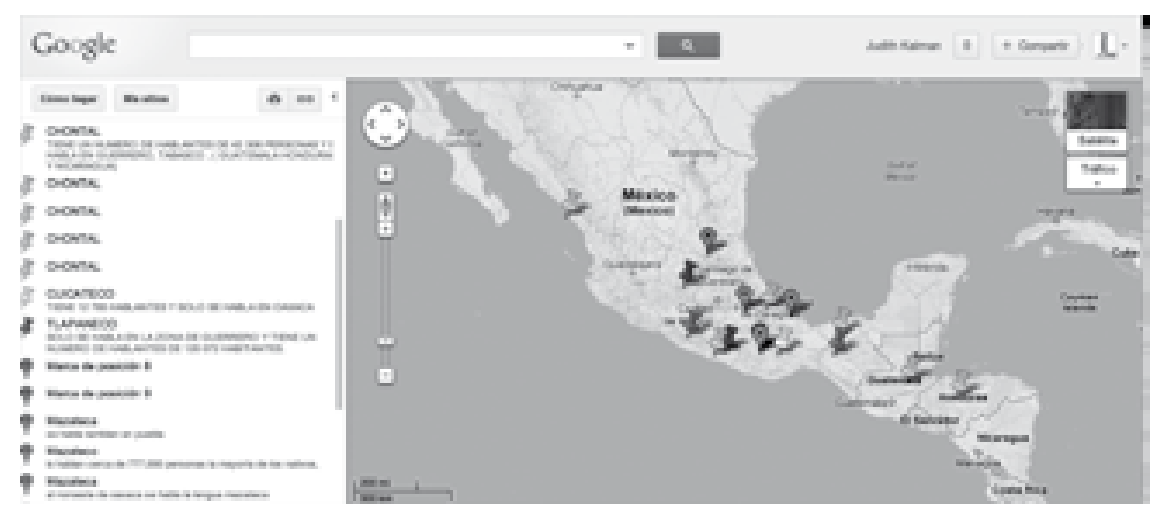

Fuente: Archivo del proyecto 
A continuación, organizó a sus estudiantes en parejas - una innovación para ella-, y les asignó a cada par una lengua a investigar. Para ello, les pidió que produjeran un video corto que documente la ubicación, la cultura, las costumbres y la vida cotidiana de las diferentes comunidades lingüísticas. También, solicitó a sus alumnos que escribieran textos cortos, que buscaran imágenes, y que incluyeran un mapa y sus fuentes de información. Los que completaron la tarea cumplieron sus expectativas en buena medida, aunque no todos entregaron un producto final. Al explicar esta tarea, Hilda subrayó la idea de que no deberían copiar y pegar textos. Encontró indicios de los intentos que habían hecho los estudiantes para utilizar la información que encontraron en diferentes formas. Por ejemplo, dos niñas resumieron y articularon información de más de una fuente, algo nuevo en el salón de Hilda. Otro estudiante desarrolló aun más el mapa de las lenguas indígenas anteriormente descrito, e incluyó el número de hablantes de cada grupo lingüístico. Un tercer estudiante escribió frases como: «De acuerdo al censo mexicano del 2005 cuenta con 49.000 hablantes», como una forma de referirse a la información que había encontrado sin copiarla. Cabe anotar que los lectores notarán el uso no convencional de «de acuerdo al» en lugar de «de acuerdo con», una expresión que sugiere que se trata de la redacción del estudiante. Más allá de ello, cada una de estas respuestas refleja los esfuerzos de Hilda para rediseñar las tareas encomendadas y redefinir sus expectativas con relación a sus estudiantes.

\section{Lucía: «¿Cuál es el propósito?»}

Lucía es una joven maestra, que cuenta con solo tres años de experiencia en el aula. Es profesora de Español en segundo de secundaria en una escuela secundaria de tamaño medio, ubicada en el extremo sur oriental de la ciudad de México. Ha desarrollado varias prácticas tecnológicas; informó que, desde antes de llegar a LETS, utiliza la computadora y el Internet «para investigar, para comunicarse con los demás, y para enviar y recibir trabajos». Antes de unirse a nosotros, ya utilizaba Microsoft Word y PowerPoint en su práctica docente, y buscaba y seleccionaba videos para que los estudiantes los vieran. Está convencida de que, para que los estudiantes aprendan, necesitan entender el propósito del trabajo que se les asigna, de lo que ella espera que aprendan, y de lo que será el producto final que elaboren. Ella cree que este enfoque ayuda a los estudiantes a «apropiarse de las herramientas que son necesarias para adaptarse eficazmente a una sociedad en constante cambio».

Como parte de sus actividades en LETS, trató de establecer una relación con otra maestra del grupo, por lo cual le envió correos electrónicos y compartió su trabajo con ella. Se decepcionó cuando su colega no le respondió; sin embargo, Lucía esperaba continuar sus conversaciones más allá de las reuniones de los grupos. Respecto a este punto, se debe anotar que la colaboración docente en México es poco común, y no constituye una práctica generalizada. En octubre, presentó su uso de Google Maps para hacer reportes de libros de 
autores latinoamericanos. Pidió a los estudiantes que, primero, eligieran cinco autores y una historia de cada uno. Después de leer las historias y de investigar sobre la vida de los autores, los estudiantes los ubicaron a todos en el mapa, insertando fotografías y comentarios relacionados con las historias que habían leído. Cuando los estudiantes estaban a la mitad del proyecto, Lucía tuvo que suspenderlo, porque el Director de su escuela había organizado un curso especial sobre drogadicción que tuvo lugar en el laboratorio de computación, por lo cual ya no tenía acceso a él. Desde entonces, ha organizado actividades en torno a la escritura y a la grabación de un audio libro; la escritura de una biografía mediante el hipertexto; y, más recientemente, dibujos animados basados en acontecimientos actuales. En diciembre de 2012, Lucía abrió una página de Facebook para usar con sus estudiantes; los padres de los mismos están invitados a visitarla cada vez que quieran. Utiliza esta página para publicar información sobre las tareas y los trabajos de sus alumnos; ellos también la utilizan para enviar comentarios y hacer preguntas.

\section{Gráfico V. Página del Facebook de Lucía}

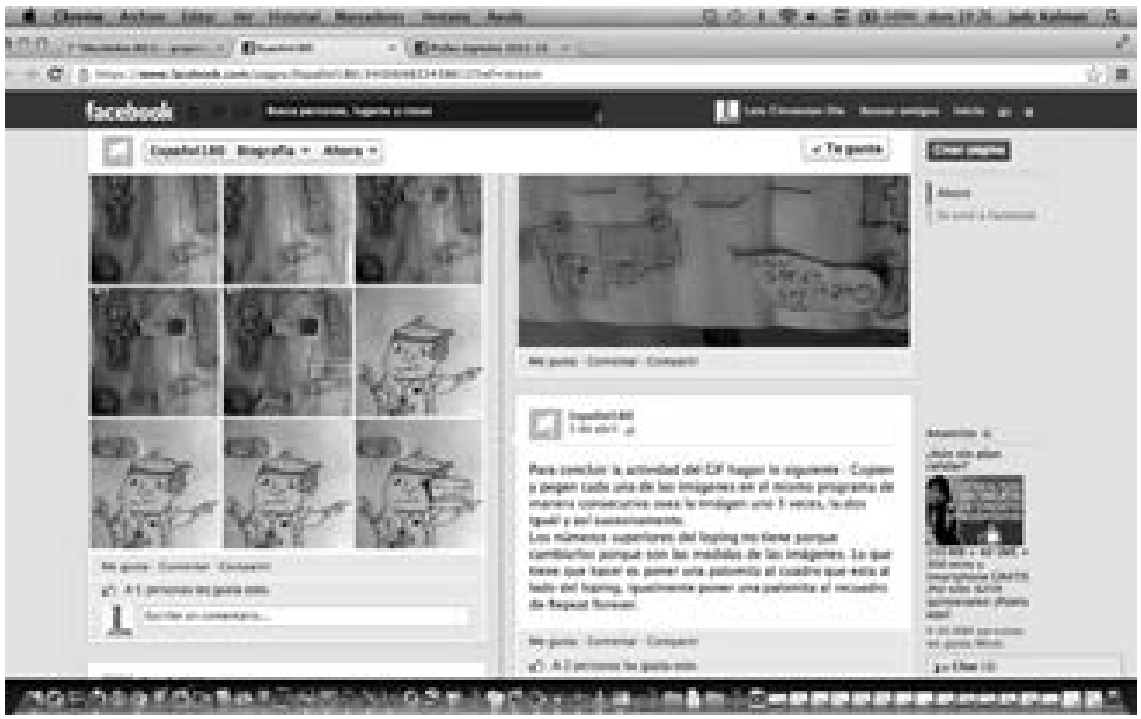

A través de esta página, Lucía envía materiales a sus estudiantes, contesta sus preguntas, recibe sus comentarios y publica su trabajo. Fuente: Archivo del proyecto

A principios de 2013, Lucía y sus alumnos trabajaron en el tema curricular «Biografía». El programa de estudios sugiere que los alumnos escriban una biografía y una lista de las características de este género. Lucía los organizó en grupos; les pidió que eligieran a alguien que conocieran, y que lo entrevistaran como actividad inicial de esta unidad. Los alumnos decidieron colectivamente preguntar a sus entrevistados acerca de sus años de infancia y de escuela, de sus 
trabajos y actividades cotidianas y sobre los momentos más importantes en sus vidas. Una vez que recolectaron esta información, los estudiantes escribieron la biografía de la persona. Lucía les enseñó a crear un hipertexto utilizando PowerPoint como la base de su texto e ilustraciones. Cada grupo desarrolló una biografía en Hypertexto para presentar a sus compañeros de clase. Este trabajo no se ha podido publicar en Facebook, debido a que no se preservaron los vínculos; por ello, Lucía optó por que sus alumnos presentaran en clase sus proyectos terminados. Antes de que comenzaran a desarrollar sus trabajos, les preguntó: «Con base en su experiencia, ¿qué es una biografía? ¿Cuáles son sus características?». Los estudiantes articularon las definiciones en ese momento y comentaron sobre lo que ellos consideraban los aspectos más importantes. Luego, procedieron a presentar su trabajo y a hacer comentarios sobre el mismo.

Gráfico VI. Página principal de la biografía de un bombero de la localidad realizada por un estudiante

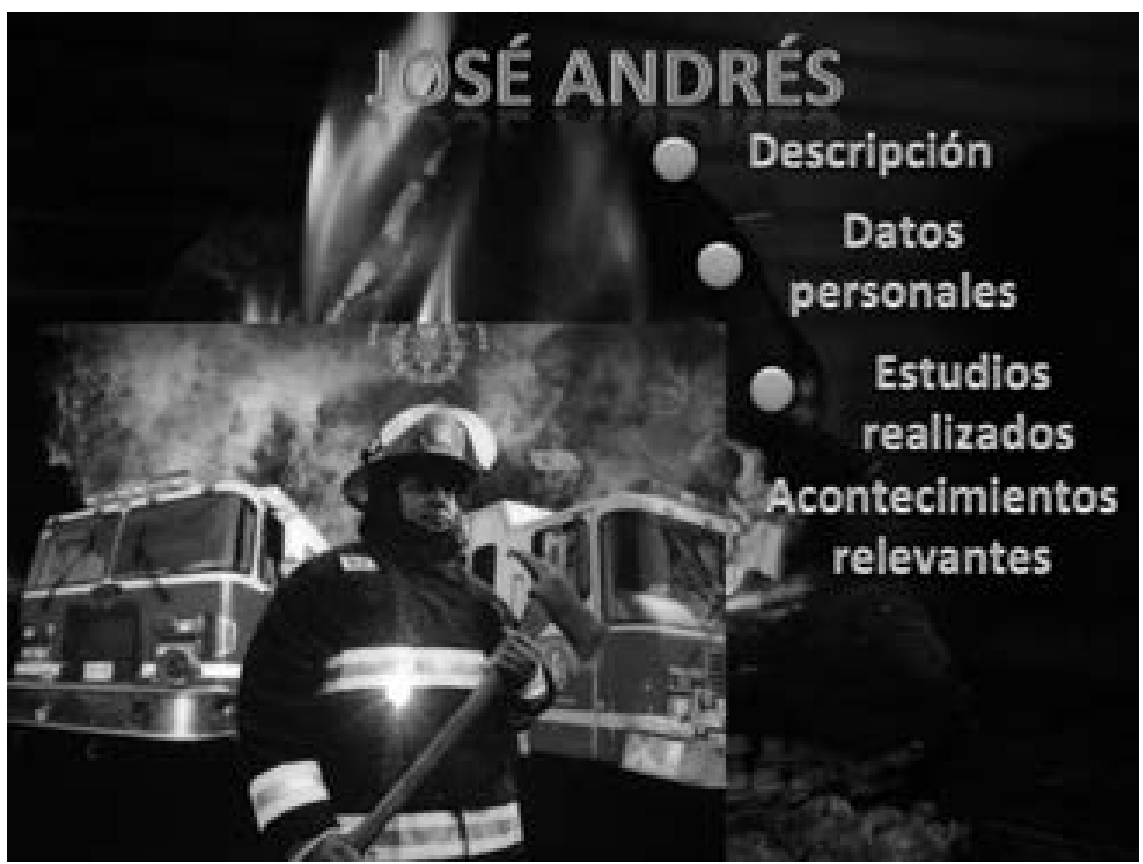

Cada tema (la descripción, información personal, educación, principales eventos) está vinculado a otras páginas mediante un hipervínculo con fotografías y textos escritos por los estudiantes.

Fuente: Archivo del proyecto 


\section{El viaje de los profesores y las trayectorias errantes}

Las descripciones de Hilda, Adriana y Lucía sobre la incorporación de la tecnología en sus salones de clase ilustran la gran diversidad y complejidad de este esfuerzo. Sus retratos muestran procesos docentes para hacer frente a una variedad de factores que afectan directamente sus decisiones cuando intentan aprender a hacer algo que ya saben hacer: enseñar (Lave, 2011). El propósito de esta sección es poner en primer plano los diversos y errantes caminos de los profesores, y explorar cómo se resolvieron la variedad de factores y de situaciones inesperadas que tuvieron un impacto sobre su manera de trabajar con sus alumnos. Si bien la experiencia de un maestro no se puede generalizar y aplicar a otros, el denominador común de esta y de otras situaciones similares de intercambio educativo es la heterogeneidad de las respuestas de los maestros a las demandas, y las muy diferentes maneras en las que los profesores recurren a sus propios medios y recursos -su experiencia, creencias, experiencia profesional, conocimientos tecnológicos, sus interacciones con los demás- para dar sentido y actuar en eventos específicos de enseñanza (Lave, 2011; De Certeau, 1988).

Al examinar la participación y los procesos de los profesores hemos encontrado lo siguiente:

Los profesores abordan su participación en proyectos de innovación como este desde distintos puntos de partida, relacionados con rutinas establecidas en el salón de clases, años de experiencia, conocimientos disciplinarios, relaciones con las autoridades escolares y los compañeros de trabajo, y prácticas tecnológicas (Jackson, 1990; Guerrero, 2011; Kalman y Guerrero, 2013; Warschauer, 2002).

A pesar de que el discurso oficial alienta y demanda el uso de la tecnología en la escuela, el trabajo de los docentes suele bloquearse por las necesidades institucionales y las decisiones de los demás (MacFarlane, 2003; Kalman y Rendón, 2014).

Al formar parte del proyecto LETS, los profesores utilizan la tecnología digital y discuten sus posibilidades y limitaciones; $y$, frecuentemente, se encuentran en una situación en la que deben confrontar diferentes creencias y enfoques pedagógicos que a menudo son contradictorios. Esto constituye una experiencia que puede ser nueva para ellos.

Hay tradiciones de enseñanza profundamente arraigadas que, a menudo, opacan otras opciones para organizar el aprendizaje.

Estos bocetos, también, ilustran la manera en la que los profesores toman diferentes decisiones para satisfacer las demandas institucionales y sociales del uso de la TIC-D con los estudiantes. Algunos se deslizan con relativa facilidad a través de los aspectos operativos de la tecnología, y también se ocupan de las complejidades y los inconvenientes a medida que estos surgen. Otros luchan para entender cómo podrían reorganizar el trabajo en clase para tomar en cuenta el espíritu de la cultura digital, solo para descubrir que esta abre muchos 
nuevos problemas y desafíos, y que continuamente tienen que replantearse sus decisiones e incrementar sus opciones. Otros simplemente se aferran a «lo de siempre» en términos de enseñanza, y utilizan el teclado y la pantalla para reiterar su modus operandi ya establecido. Si bien todos los profesores mencionados en este artículo confrontan el uso de la tecnología y la incorporación de elementos similares en su trabajo, a nosotros nos parecen muy distintas su «manera de articularlos» (De Certeau, 1988).

Las trayectorias errantes aquí descritas incluyen la negociación a través de políticas, infraestructura inadecuada, tradiciones de enseñanza, problemas de diseño de tareas, búsqueda de soluciones para caos inesperados, creencias, antecedentes profesionales y la integración de algunas de las ideas y propuestas de LETS. Cabe aclarar que, debido a que este proyecto está en proceso, existe un cierto riesgo de llegar a conceptualizaciones prematuras. Sin embargo, en aras de la discusión, tanto el trabajo como el aprendizaje y la participación de estos profesores pueden ser entendidos a través de tres metáforas, todas ellas relacionadas con los viajes o con la idea de ir de un lugar a otro.

\section{Gráfico VII. Trayectorias errantes: enseñando con tecnología}

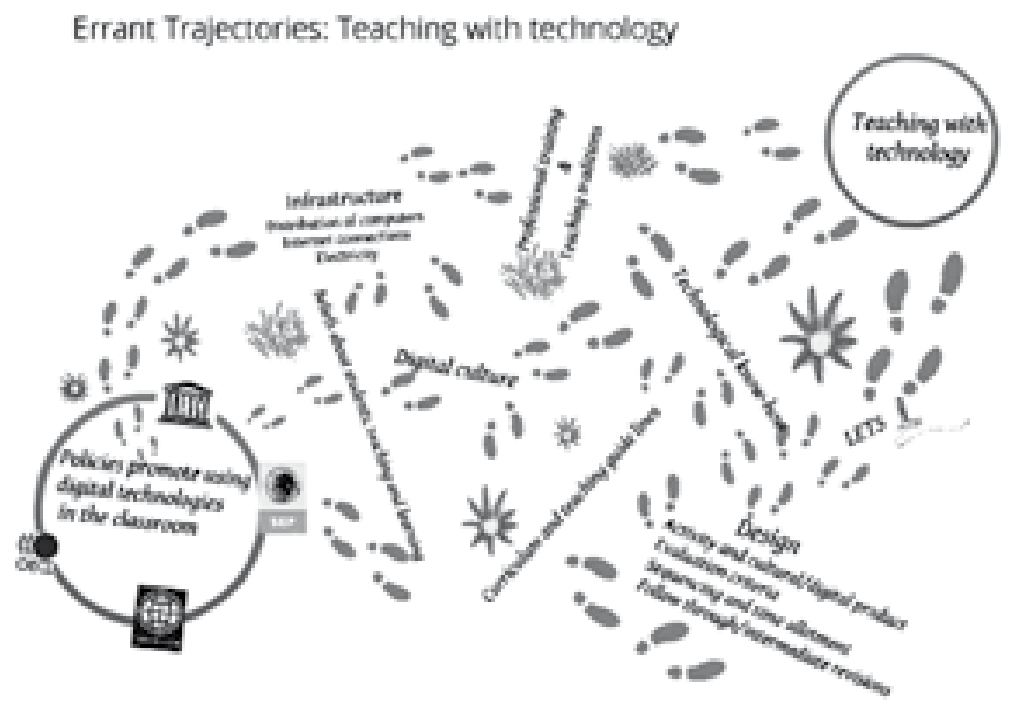

Fuente: 0 meni Elaboración propia

Algunos profesores parecen tener un itinerario directo. A medida que pasan a través de diversos contextos sociales y «a través de múltiples prácticas sociales en diversas instituciones» (Gee, Hull y Lankshear, 1996), recogen recuerdos de diferentes lugares (know-how tecnológico, nuevos métodos de enseñanza y actividades innovadoras) y los articulan con sus estudiantes en una 
variedad de formas. Esto no quiere decir que no se encuentran con contingencias inesperadas u obstáculos imprevistos, pero logran movilizar sus recursos o encontrar otros nuevos para resolver problemas y continuar con su trabajo (Kress, 2003; De Certeau, 1988). De la misma manera en la que el viajero puede encontrar el charco inesperado o un desvío en el camino, estos profesores se encuentran con laboratorios de computación cerrados, estudiantes que no cooperan, computadoras que no guardan el trabajo o días en los que no hay Internet en la escuela. Así, modifican su actividad, reorganizan y redistribuyen el tiempo, o introducen una nueva opción para los estudiantes (Rendón, 2012; Guerrero, 2011).

En este marco, a pesar de los pocos años que lleva enseñando, Lucía es una viajera experimentada. Ella está a gusto con la tecnología y su trabajo en el aula sugiere que a menudo se replantea la forma de enseñar y lo que quiere enseñar y conseguir; y que logra sortear las limitaciones de los planes de estudio y los obstáculos institucionales que enfrenta. Utiliza su know-how tecnológico y su comprensión de la cultura digital para organizar productos ambiciosos; se sirve de Facebook para comunicarse con sus alumnos y publicar sus trabajos, y diseña tareas en las que los estudiantes utilizan múltiples formas de representación y desarrollan sus propias ideas (Mattherwman, 2004).

Otros maestros parecen recorrer un camino errante, una red de caminos secundarios relacionados entre sí. Hilda está familiarizada con la tecnología y la usa en su vida diaria, pero hasta ahora no la ha utilizado mucho en su práctica docente. No obstante, la incorporación de la computadora para el diseño de objetos culturales (NLG 1996) y las búsquedas en Internet la han hecho cuestionar creencias muy arraigadas acerca de su papel como maestra. Al ver el trabajo de sus estudiantes, empezó a darse cuenta de que la mayoría se limitaba a copiar y a pegar desde otras fuentes electrónicas. Esto la llevó a pensar más acerca de la enseñanza y el aprendizaje, sobre su manera de asignar tareas, y sobre lo que ella esperaba que los estudiantes hicieran (Sutherland et ál., 2009). Posteriormente, volvió a recorrer el territorio conocido y reconsideró su manera establecida de asignar trabajos, en particular, la forma en la que se formulaban las preguntas en su salón de clases. Esto, a su vez, atrajo hacia ella nuevas situaciones y desafíos.

Asimismo, volvió a repasar algunas de las tareas que había asignado, intentó nuevas formas de organizar el contenido y el trabajo de los estudiantes, y repensó algunas de sus expectativas en relación con sus estudiantes. Uno de los cambios observables en su práctica es el hecho de haber reconocido los diferentes modos de representación como válidos para el trabajo académico, lo cual se percibe a través de sus intentos por diseñar actividades que no se limitan a escribir un trabajo, o a crear una tabla o un mapa conceptual.

Por último, la tercera metáfora es la del viajero en un tour programado. El destino está establecido, las comidas están programadas con antelación y los medios de transporte ya están asegurados. Todo lo que este viajero tiene que hacer es tomar a tiempo el autobús. No hay tiempo para dar un paseo, no hay 
necesidad de hacer frente a lo inesperado. Aquí el profesor utiliza la tecnología digital para "hacer lo de costumbre», y evita vagar lejos de la actividad planificada, incluso cuando experimenta baches en la carretera o desvíos involuntarios. Adriana parece ser este tipo de maestra. A diferencia de las otras, ella no retrocede y toma un camino diferente para ver a dónde podría llevarla.

Lo que sucede en su clase está muy alineado con la visión tradicional del aula, con lo que Rogoff, Paradise, Mejía y Correa-Chávez definen como «estructura jerárquica, organizada mediante roles fijos en los que alguien administra la participación de los demás, actuando como jefe» (2003, p. 184). Ella no cuestiona su rol ni su posición (y mucho menos la de sus alumnos), y se adhiere a los principios de la enseñanza autoritaria al decirles a sus estudiantes qué hacer, al tener ella la última palabra y al descalificar sus trabajos sin dudarlo. Aquí, Adriana hace las preguntas, decide lo que es útil y lo que no lo es, y no está abierta a sugerencias. Asigna tareas que se pueden resolver copiando una definición, dando respuestas de sí/no, o localizando mapas y diagramas y simplemente reproduciéndolos. Parece comprender los aspectos formales de la utilización de la tecnología (los estudiantes, después de todo, están en la computadora), pero no está abierta (aún) a algunos de los principios del aprendizaje en un medio digital. Ella cree que está innovando por el simple hecho de utilizar la computadora, pero -a pesar de las affordances que ofrecen la computadora y la cultural digital- lleva a cabo pocos cambios en su práctica docente y preserva lo que siempre ha hecho.

\section{Más allá de las explicaciones tradicionales}

La premisa de este artículo es que, dentro de nuestro estudio, los esfuerzos de las profesoras para incorporar la tecnología en su trabajo son el resultado de la integración de elementos complejos, heterogéneos y a menudo contradictorios. El argumento aquí es que las explicaciones comunes -tales como la edad, la falta de oportunidades de capacitación o la no disponibilidad de materialesno acaban de dar cuenta del por qué algunos profesores hacen lo que hacen. Cada uno de estos puede ser un factor que contribuya a explicarlo, pero en sí mismos no nos permiten tener un conocimiento más profundo de las dificultades que enfrentan los maestros, ni tener una visión clara sobre sus decisiones y acciones subsecuentes. Hemos presentado retratos de maestras con diferentes posturas hacia la tecnología y la enseñanza, y hemos demostrado que el software específico no es necesario para la innovación. Todos nuestros profesores han tenido la misma oportunidad de desarrollo profesional a través de su participación en LETS, y, sin embargo, sus respuestas -como lo ejemplifican los tres retratos aquí presentados- son muy diferentes.

El análisis aquí presentado ilustra el contexto intensamente contradictorio en el que se encuentran los profesores en México. Por un lado, son alentados e incluso presionados por el discurso oficial, la política educativa nacional e internacional, y la opinión pública, para utilizar la tecnología en la escuela, 
para incorporar el Internet a sus recursos y a su práctica docente, y «ampliar el acceso al aprendizaje, mejorar la calidad y garantizar la inclusión» (Unesco, 2013). Por otro lado, tienen que encontrar formas de sortear condiciones, tales como equipos que tienen un uso restringido, falta de acceso al laboratorio de computación, limitaciones de tiempo y un programa de estudios complejo y extenso. Como se muestra aquí, la utilización de la computadora y el Internet puede ser para los profesores un camino cuesta arriba de principio a fin.

También, se enfrentan a la necesidad de integrar sus creencias sobre el aprendizaje, los estudiantes y su papel como maestros, con lo que la cultura digital tiene que ofrecer. A pesar de la presencia física de las computadoras, la investigación en LETS (Guerrero, 2011; Guerrero y Kalman, 2010, 2011; Rendón, 2012; Hernández, en proceso; Kalman y Guerrero, 2013; Kalman y Hernández, en prensa; Kalman y Rendón, 2014; Solís, 2009) y la investigación de otros (Leu 2002; Law 2004; Sutherland et ál., 2004; Cuba, 2000; Lankshear y Knobel, 2011; Rojano, 2003) han demostrado que esto no es suficiente para transformar la enseñanza o mejorar el aprendizaje de manera sustancial. A menos que las bases y los principios básicos de la escuela tradicional sean abordados, examinados y cuestionados directamente, parecen quedar intactos con o sin computadoras o Internet. Como lo señala Knobel (2011), en el surgimiento y la diseminación de las nuevas alfabetizaciones y la tecnología digital, las escuelas están atrasadas.

Ello responde a que la incorporación de la tecnología en las escuelas depende en gran medida de la manera en la que los profesores la incluyen en su práctica docente, y de cómo se apropian de sus posibilidades más allá de su operación. Implica una construcción no solo de los múltiples usos y herramientas de la tecnología, sino también de la comprensión de los valores, las prioridades -el ethos- de la cultura digital, incluyendo los aspectos del aprendizaje. Las trayectorias errantes de los maestros son el resultado de su articulación particular de los múltiples y heterogéneos elementos encontrados y de los obstáculos con los que tropiezan al trabajar en la incorporación de la tecnología en sus salones de clase. Esto nos recuerda cómo una transformación exitosa de la práctica docente puede $-\mathrm{y}$, a menudo, lo hace- generar nuevos problemas a resolver; y cómo el desarrollo profesional en sí mismo es rara vez un camino fácil. Para que tanto las políticas como el desarrollo profesional sean eficaces, tendrán que tomar en cuenta las trayectorias errantes de los maestros. Tendrán que proporcionar múltiples oportunidades para modelar nuevas prácticas para el aprendizaje docente, para probar diferentes enfoques de enseñanza y para reflexionar con otros.

\section{Agradecimientos}

Agradezco al Consejo de Ciencia y Tecnología en México por apoyar la investigación en curso del proyecto Los Profesores y las TIC: la apropiación del 


\section{Nota biográfica}

La Dra. Judith Kalman es Profesora Investigadora del Departamento de Investigaciones Educativas (DIE) del Centro de Investigaciones y de Estudios Avanzados del I.P.N (Cinvestav) desde 1993. Realizó estudios de Licenciatura en Lengua y Literaturas Hispánicas en la Universidad Nacional Autónoma de México, y de Doctorado en Educación, con especialidad en Lenguaje y Alfabetización, en The Graduate School of Education de la Universidad de California, Berkeley. Especialista en la construcción social de la lengua escrita, actualmente, coordina el Laboratorio de Educación, Tecnología y Educación en el DIE, donde se estudia la incorporación y el uso de las tecnologías de información, comunicación y diseño en contextos educativos y situaciones de aprendizaje. Asimismo, investiga el uso de las tecnologías digitales en el mundo social.

\section{Referencias}

Barton, D. y Hamilton, M. (1998). Local Literacies. Reading and Writting in One Community. Londres: Routledge.

Barton, D. (2012). Participation, deliberate learning, and discourses of learning online. Language and Education, 26 (2), 139-150.

Bigum, C. y Lankshear, C. (1997). Digital Literacies and Technologies in Education. Queensland: Commonwealth Department of Employment, Education, Training and Youth Affairs.

Buckingham, D. (2007). Beyond technology: Children's learning in the age of digital culture. Cambridge: Polity

Burbules, N. (2011). ¿Cuántos docentes utilizan las TIC? En S. Gvirtz y C. Necuzzi (Comps.), Educación y tecnologías: las voces de los expertos. Caba: Anses.

Collins, J. y Blot, R. (2003). Literacy and Literacies. Texts, Power and Identity. Cambridge: Cambridge University Press.

Cuban, L. (2000). Oversold and underused. Computers in the classroom. Cambridge, MA: Harvard University Press.

De Certeau, M. (1988). The Practice of Everyday Life. Berkeley, California: Universtiy of California.

Dyson, A. (1996). Writting Superheroes: Contemporary Childhood, Popular Culture and Classroom Literacy. New York: Teachers College Press.

Gee, J. (2003). What video games have to teach us about learning and literacy. New York: Palgrave (Disponible en español: Gee, James Paul (2004): Lo que nos enseñan los videojuegos sobre el aprendizaje y el alfabetismo. Málaga: Ediciones Aljibe) 
Gee, J. (2006). Situated Language and Learning. A critique of traditional schooling. Londres/New York: Routledge.

Gee, J., Hull, G. y Lankshear, C. (1996). The New Work Order: Behind the Language of the New Capitalism. Boulder: Westview Press A Division of Harper Collins Publishers.

Geertz, C. (1983). Local Knowledge. New York: Basic Books.

Guerrero, I. (2011). Ahí está el detalle: Cambios minúsculos, rutas opacas y tecnologías míticas en la enseñanza de la geografía en secundaria. (Tesis de Doctorado en Investigación Educativa), Centro de Investigación y Estudios Avanzados, Ciudad de México.

Guerrero, I. y Kalman, J. (2010). La inserción de la tecnología en el aula: estabilidad y procesos instituyentes en la práctica docente. Revista Brasileira de Educaçao, 15 (44), 213-229.

(2011). Matices en la inserción de tecnología en el aula: posibilidades de cambio en las prácticas docentes. Cuadernos Comillas, 1 (1).

Hernández, O. (en proceso). Aprendizaje y prácticas sociales en torno al uso de tecnologías de la información y la comunicación en una comunidad suburbana de la Ciudad de México. (Tesis de Doctorado en Investigación Educativa). Centro de Investigación y Estudios Avanzados, México D.F.

Jackson, P. W. (1990). Life in Classrooms. New York: Teachers' College Press.

Jara, I. (2007). Las políticas de tecnología para escuelas en América Latina y el mundo: visiones y lecciones. Santiago de Chile: Comisión Económica para América Latina y el Caribe.

Jenkins, H. (2006). Confronting the Challenges of Participatory Culture: Media for the 21st Century. Boston: MacArthur Foundation.

Johnson, L., Adams, S. y Cummins, M. (2012). NMC Horizon Report 2012 K-12 Edition. Austin: New Media Consortium.

Kalman, J. y Guerrero, E. (2013). A social practice approach to understanding teachers learning to use technology and digital literacies in their classrooms. E-Learning and Digital Media, 10 (3), 260-275.

Kalman, J. y Rendón, V. (2014, setiembre). Use before know-how: Learning to teach with technology in a Mexican public school. Qualitative Studies in Education, 27 (8), 974-991.

Kress, G. (2003). Literacy in the New Media Age. Londres/New York: Routledge.

Kuznetsov, Y. y Dahlman, C. J. (2008). Mexico's Transition to a Knowledge-Based Economy. WBI Development Studies. Washington, DC: The World Bank.

Lankshear, C. y Knobel, M. (2011). New Literacies: Everyday Practices \& Classroom Learning ( $3^{\mathrm{a}} \mathrm{ed}$.). Londres: Open University Press.

Lave, J. (2011). Apprenticeship in critical ethnographic practices. Chicago: University of Chicago Press. 
Lave, J. y Wenger, E. (1991). Situated Learning. Legitimate Peripheral Participation. Cambridge: Cambridge University Press.

Law, N. (2004). Teachers and teaching innovations in a connected world. En A. Brown y N. Davis (Eds.), Digital tecnology, communities and education (pp. 145-163). Londres/New York: Routhledge Falmer.

Leu, D. (2002). The New Literacies: Research on Reading Instruction with the Internet. En Samuels (Ed.), Reading Research Handbook (pp. 310-336). Delaware: International Reading Association,

Leu, D., Hillinger, M., Loseby, P., Balcon, M., Dinkin, J., Eckels, M., Johnson, J., Mathews, K. y Raegler, R. (1998). Grounding the Design of New Technologies for Literacy and Learning in Teachers' Instructional Needs. En D. Reinking, M. McKenna, L. Labbo y R. Keiffer (Eds.), Handbook of Literacy and Technology. Transformations in a Post Typographic World (pp. 203221). Mahway, NJ: Lawrence Erlbaum Associates.

Matthewman, S. (2004). What does multimodality mean for English? Creative Tensions in Teaching New Texts and New Literacies. Education, Communication and Information, 4 (1), 133-176.

McFarlane, A. (2003). El aprendizaje y las tecnologías de la información. México D.F: Secretaría de Educación Pública.

Mulcahy, D. (2012). Thinking teacher professional learning performatively: a socio-material account. Journal of Education and Work, 25 (1), 121-139.

NLG (1996). A Pedagogy of Multiliteracies: Designing Social Futures Harvard Educational Review, 66 (1), 60-92. doi: A Pedagogy of Multiliteracies Designing Social Futures.mht

Rendón, V. (2012). La computadora llega al aula: la incorporación de las tecnologías digitales a la práctica docente. Un estudio de caso. (M.S. Educational Research). México D.F.: Centro de Investigación y Estudios Avanzados.

Rogoff, B., Paradise, R., Mejía, R. y Correa-Chávez, M. (2003). Firsthand Learning through participation. Annu. Rev. Psychol., 54, 175-203.

Rojano, T. (2003). Incorporación de entornos tecnológicos de aprendizaje escolar: proyecto de innovación educativa en matemáticas y ciencias en escuelas secundarias públicas de México. Revista Iberoamericana de Educación, 33, 35-165.

Scribner, S. y Cole, M. (1981). The psychology of literacy. Cambridge, MA.: Harvard University Press.

Secretaría de Educación Pública (2009). Cajita de Herramienta. Guía Metodológica. Línea de Trabajo. Uso didáctico de las Tecnologías de la Información y Comunicación. México D.F.: Secretaría de Educación Pública.

D.F.: Secretaría de Educación Pública.

(2011). Español. Programa de Estudio. México 
Solis, A. (2009). El uso del aula de medios en una escuela secundaria de la Ciudad de México (Tesis de Maestría en Investigación Educativa). Centro de Investigación y Estudios Avanzados, México D.F.

Street, B. (1995). Social Literacies: Critical Approaches to Literacy in Development, Ethnography and Education (Vol. 7). Londres/New York: Longman.

Sunkel, G. (2006). Las tecnologías de la información y la comunicación (TIC) en la educación en América Latina. Una exploración de indicadores. Santiago de Chile: Comisión Económica para América Latina y el Caribe, y Unesco.

Sutherland, R., Armstrong, V., Barnes, S., Brawn, R., Breeze, N., Gall, M., Matthewman, S., Olivero, F., Taylor, A., Triggs, P., Wishart, J. y John, P. (2004). Transforming teaching and learning: embedding ICT into everyday classroom practices. Journal of Computer Assisted Learning, 20, 413-425.

Sutherland, R., Robertson, S. y John, P. (2009). Improving Classroom Learning with ICT. Londres: Routledge.

United Nations Educational, Scientific and Cultural Organization (2013). ICT in Education: Policy. Unesco. Recuperado de http://goo.gl/hwQGZ

Vygotsky, L.S. (1978). Mind in Society: The development of higher psychological processes. Cambridge, MA: Cambridge University Press.

Warschauer, M. (2002). Reconceptualizing the Digital Divide. First Monday, 7 (7). Recuperado de

http://firstmonday.org/htbin/cgiwrap/bin/ojs/index.php/fm/article/ view $/ 967 / 8$ 